\title{
NEUROMUSCULAR TAPING TEKNIK KOMPRESI MENINGKATKAN EXPLOSIVE POWER DAN MAXIMUM SPEED LARI 100 METER
}

\author{
Tri Setyo Utami ${ }^{1)}$, Bambang Purwanto ${ }^{2)}$, Edy Mintarto ${ }^{3)}$ \\ 1),2)Program Studi Ilmu Kesehatan Olahraga \\ Pascasarjana Universitas Airlangga \\ 3) Pascasarjana Universitas Negeri Surabaya \\ E-mail : tri.setyo.utami-2017@,fk.unair.ac.id
}

\begin{abstract}
Sprint 100 meter that has sprint phase such as acceleration, maximum speed, and deceleration which can improvement performance in sprinting ability. The aim of this study to showing effect of neuromuscular taping compression technique on explosive power and sprint 100 meter to provide increased muscle functional ability, tendon efficiency, and joint stability by stimulating the nerves. This study is an experimental research field with a pre-test and post-test control group design. Twenty-two samples were selected from the population of East Java sprint athletes based on the consecutive sampling technique which was divided into two groups randomly. Neuromuscular compression technique are given Intervention in the gastrocnemius area on treatment group after pre-test. The explosive power are using tandem vertical jump test measurenment and infared electrics time respectively. The paired sample T-test are showing increases in expolsive power in the gastrocnemius and sprint 100 meter maximum phases $(p<0.05)$. the conclusion the study is neuromuscular taping compression technique can be increases explosive power and maximum speed of 100 meter.
\end{abstract}

Keywords: Explosive power; maximum speed; NMT compression.

\begin{abstract}
ABSTRAK
Lari 100 meter memiliki fase sprint seperti akselerasi, maksimum speed, dan diselerasi yang dapat mempengaruhi performa pada kecepatan lari. Penelitian untuk mengetahui pengaruh pemasangan teknik kompresi neuromuscular taping terhadap explosive power dan waktu tempuh lari 100 meter dengan memberikan manfaat pada kemampuan peningkatan fungsional otot, efisiensi tendon, dan stabilitas sendi dengan cara menstimulasi saraf. Jenis penelitian ini adalah field experimental menggunakan pre test dan post test control group design. Dua puluh dua sampel

Cara mengutip: Utami, T. Setyo., Purwanto, Bambang \& Mintarto, Edy. (2020). Neuromuscular Taping Teknik Kompresi meningkatkan Explosive Power dan Maximum Speed lari 100 Meter. Care:Jurnal Ilmiah Ilmu Kesehatan, 8(3), 464-471
\end{abstract}


dipilih dari populasi atlet PASI Jawa Timur berdasarkan consecutive sampling tehnique dibagi menjadi dua kelompok secara random. Neuromuscular teknik kompresi diberikan intervensi kepada kelompok perlakuan setelah melakukan pre-test dengan explosive power dan lari 100 meter pada area otot gastrocnemius. Indikator pengukuran explosive power menggunakan tandem vertical jump test dan infrared electrics time. Hasil uji paired sample t-test menunjukkan peningkatan explosive power pada gastrocnemius dan meningkatkan kecepatan lari 100 meter pada fase maksimal $(\mathrm{p}<0.05)$ Disimpulkan dari penelitian ini dapat disimpulkan bahwa neuromuscular taping teknik kompresi dapat meningkatkan explosive power dan maximum speed lari 100 meter.

Kata Kunci: Explosive power, maximum speed; NMT kompresi.

\section{PENDAHULUAN}

Aktivitas fisik memberikan respon pada sistem musculoskeletal, kardiorespirasi, serta sistem metabolisme. Latihan olahraga dapat meningkatkan aktivitas gerak pada musculoskeletal salah satunya pada lari sprint terdapat gerak tubuh pada ekstremitas atas dan ekstremitas bawah dengan mekanisme sprint block start membutuhkan explosive power (Amin, 2014), fase sprint dipengaruhi oleh akselerasi, maksimal speed dan diselerasi yang bertujuan untuk meningkatkan kemampuan performa lari sprint (Majumdar and Robergs, 2011).

Fase sprint saling berkaitan dalam performa maksimal, ditemukan paling lemah pada rerata atlet Indonesia pada fase akselerasi pada 40 meter pertama yang dapat menurunkan performa pada fase maksimum (Veraamani, 2018) fase akselerasi jarak 0-30 meter dipengaruhi oleh kemampuan motorik yang paling utama bersifat konsentrik dalam menghasilkan waktu yang singkat (Mackala et al., 2013 ; Mackala et al.,2015), maximum speed dihasilkan melalui karakteristik morfologi, fisiologis, mekanisme energi, usia, jenis kelamin, kemampuan motorik dan koordinasi otot dengan jarak 30-60 meter (Mackala, 2007) sedangkan diselerasi terjadi karena penurunan frekuensi langkah terutama pada 20 meter terakhir menjelang garis finish yang dipengaruhi oleh kelelahan sentral dan perifer sehingga kapasitas kemampuan motorik dan frekuensi antara neuron dan otot menurun (Semmler and Enoka 2000) solusi selama ini dalam meningkatkan performa saat ini dengan memperbaiki teknik block start, faktor psikologis dan stretch shortening cycle (SSC) untuk meningkatkan performa kecepatan dan power (Maćkała, Fostiak and Kowalski, 2015).

Upaya intervensi untuk meningkatkan performa atau prestasi menggunakan aplikasi neuromuscular taping teknik dekompresi dapat meningkatkan kekuatan otot dan waktu tempuh (Endaryanto, 2018) 
namun, teknik dekompresi ini bersifat pemanjangan otot yang mempengaruhi elastisitas tendon lebih panjang, sedangkan mekanisme berlari fase akselerasi kemampuan motorik yang paling utama bersifat konsentrik dengan memiliki stimulasi pemendekan otot yang dapat meningkatkan kemampuan fungsional otot ( Blow, 2012 ; Davis, 2010). Aplikasi neuromuscular taping teknik kompresi salah satu intervensi terbaru untuk meningkatkan kemampuan performa otot pada atlet.

Aplikasi neuromuscular taping teknik kompresi adalah teknik dengan pemasangan adhesive tape aplikasi konsentrik dengan tujuan untuk meningkatkan kekuatan, efisiensi tendon dan meningkatkan fungsional otot namun hanya bisa digunakan waktu yang terbatas karena dapat menyebabkan kram (Blow, 2012).oleh sebab itu aplikasi teknik kompresi neuromuscular taping dilakukan, karena diduga dapat meningkatkan explosive power dan waktu tempuh lari 100 meter.

\section{METODE PENELITIAN}

Jenis penelitian ini menggunakan Field experimental dengan menggunakan pre test dan post test control group design. Sampel penelitian menggunakan rumus lameshow (Endaryanto, 2018) yang diambil dengan consecutive sampling pada atlet sprint
Persatuan Atletik Seluruh Indonesia (PASI) Jawa Timur yang di bagi menjadi dua kelompok secara random. Sampel didapatkan berdasarkan kriteria inklusi berjenis kelamin laki-laki, usia 15-25 tahun, dan atlet mengikuti latihan intensif. Data yang dikumpulkan berupa data hasil pemasangan neuromuscular taping terhadap explosive power dengan vertical jump test dan maximal speed lari 100 meter $(\mathrm{m} / \mathrm{s})$. Analisa data menggunakan uji paired sample T-test $(\mathrm{p}=0,05)$.

Protokol pengukuran explosive power menggunakan tandem vertical jump test dan infrared electric times pada lari 100 meter. Kelompok perlakuan diberikan intervensi pemasangan neuromuscular taping teknik kompresi pada area gastrocnemius oleh fisioterapis yang berlisensi setelah melalukan pre-test. Pengukuran post-test dilakukan setelah jeda 45 menit dengan dilakukan pengukuran vertical jump dan lari 100 meterdengan beberapa fase yaitu akselerasi, maximum speed, dan diselerasi. Analisa data menggunakan aplikasi SPSS 22 yang berurutan melalui analisa deskriptif, normalitas Analisis data secara berurutan melalui analisa deskriptif, normalitashomogenitas dengan uji paired sample t-test. 


\section{HASIL}

Jumlah sampel penelitian berjumlah 22 orang dalam kelompok eksperimen dan kelompok .Analisa deskriptif dilakukan pada kriteria sampel yang meliputi usia, berat badan, tinggi badan, dan IMT.

kelompok kontrol 11 orang setiap

Tabel 1. Analisa Deskriptif Usia, Berat Badan, Tinggi Badan, dan IMT Subjek Penelitan, tahun 2019

\begin{tabular}{cccc}
\hline \multirow{2}{*}{ Variabel } & K. Eksperimen (11) & K. Kontrol (11) & \multirow{2}{*}{$\mathbf{P}$} \\
\cline { 2 - 3 } & Rerata \pm SD & Rerata \pm SD & \\
\hline Usia (tahun) & $18,00 \pm 2,75$ & $16,45 \pm 1,36$ & $0,179^{*}$ \\
Berat Badan $(\mathrm{Kg})$ & $67,28 \pm 4,59$ & $59,03 \pm 5,58$ & $0,864^{*}$ \\
Tinggi Badan $(\mathrm{m})$ & $1,72 \pm 0,04$ & $1,67 \pm 0,06$ & $0,237^{*}$ \\
IMT $\left(\mathrm{Kg} / \mathrm{m}^{2)}\right.$ & $67,36 \pm 7,33$ & $21,23 \pm 2,56$ & $0,291^{*}$ \\
\hline
\end{tabular}

Keterangan :

*: Data Berdistribusi Homogen

Hasil pengukuran dilakukan pre test dan

terjadi peningkatan pada kelompok pos test pada kelompok kontrol tanpa pemasangan NMT sedangkan kelompok eksperimen dengan nilai rata-rata $68.55 \mathrm{~cm}$ eksperimen menggunakan NMT teknik setelah dilakukan pemasangan neuromuscular kompresi. Pada gambar 1 menunjukkan taping sebaliknya, pada kelompok kontrol terjadi penurunan sebesar $63.27 \mathrm{~cm}$.

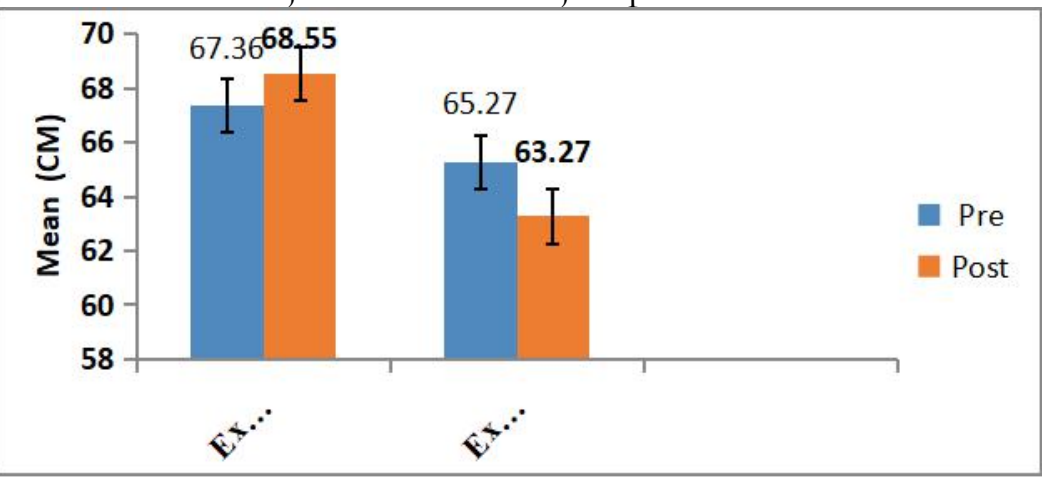

Gambar 1. Nilai rata-rata neuromuscular Taping (NMT) pada explosive power

Pemasangan neuromuscular taping teknik kompresi pada kelompok eksperimen (K.E) menunjukkan pengaruh yang signifikan terhadap kecepatan lari 100 meter setelah dilakukan pemasangan neuromuscular taping pada setiap fase dinamika kecepatan pada sprinter. Ketiga fase tersebut terdapat peningkatan catatan waktu, namun perubahan yang paling signifikan pada fase maksimal speed jarak 60 meter. Sedangkan tanpa pemasangan neuromuscular taping pada kelompok Kontrol (K.K) terjadi penurunan. Bisa dilihat pada gambar 2 . 


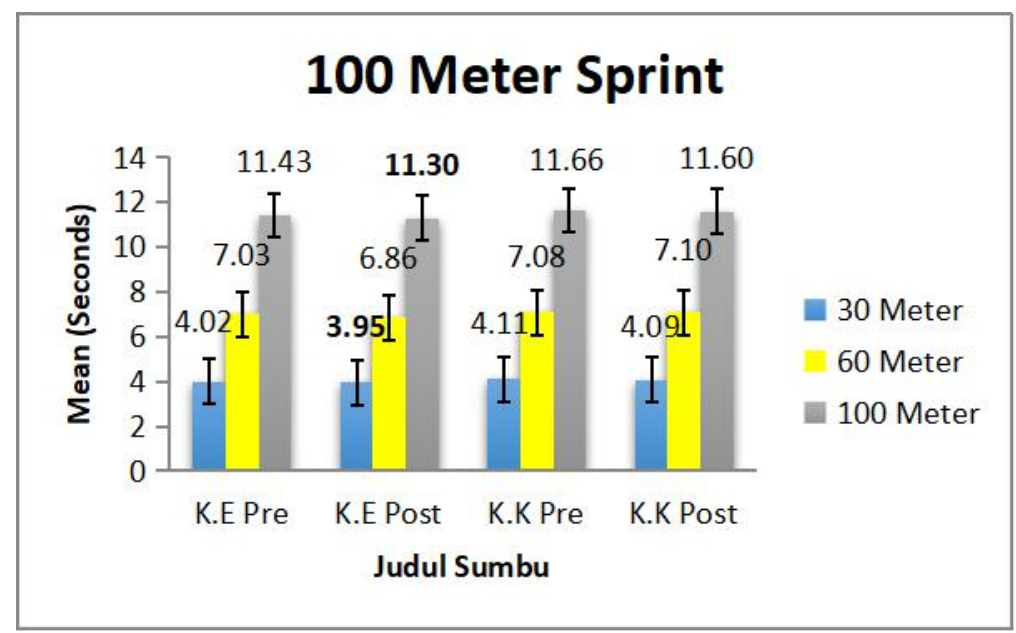

Gambar 2. Waktu tempuh lari 30, 60 dan 100 meter sebelum dan sesudah pemasangan Neuromuscular Taping teknik kompresi

Tabel 2. Analisa perkembangan fase lari sprint 100 meter

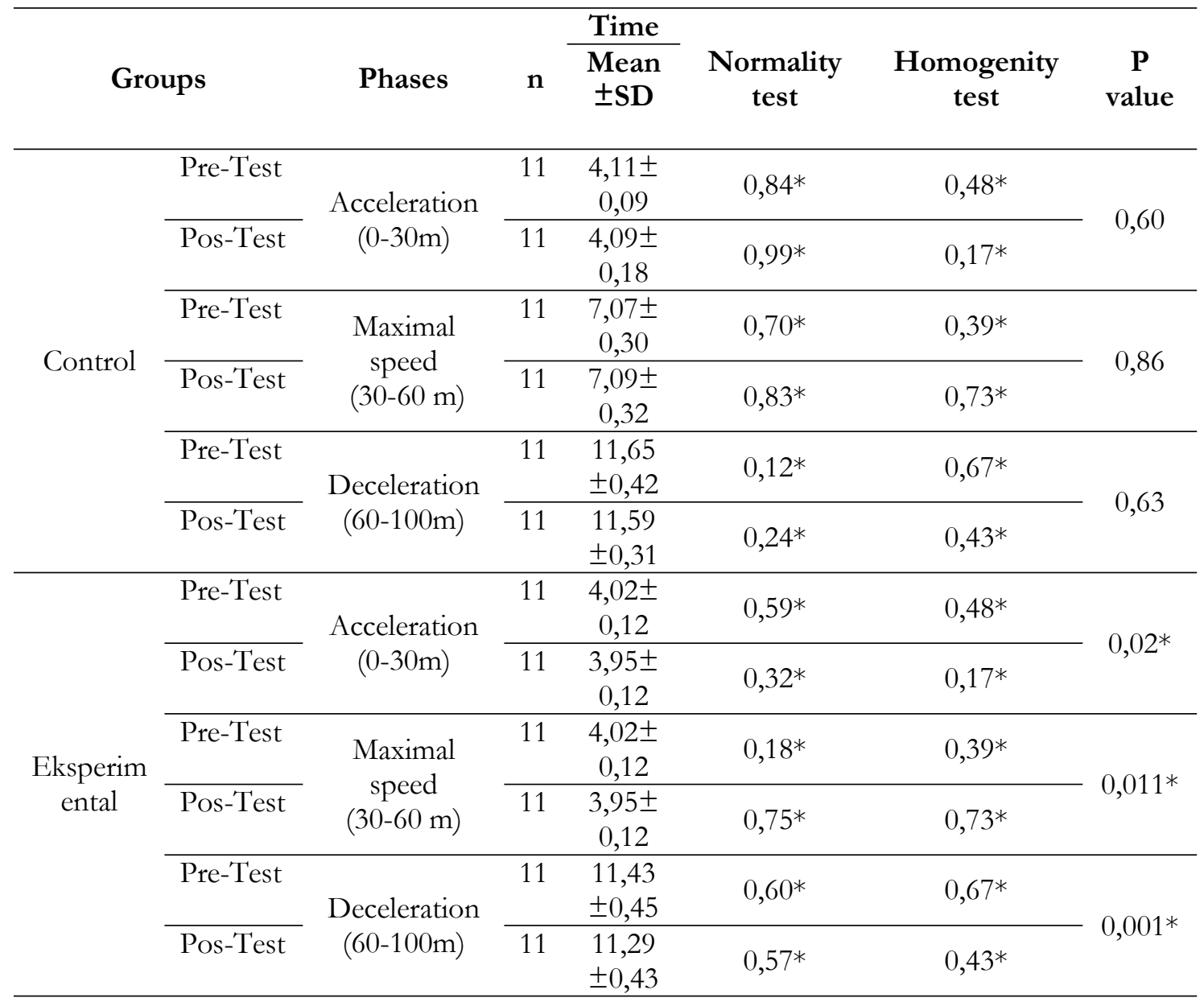

Untuk mengetahui pengaruh pemasangan neuromuscular taping pada percepatan waktu 100 meter digunakan analisa paired sample $T$ - test. Hasil analisa menunjukkan adanya pengaruh terhadap kecepatan lari 100 meter terjadi peningkatan waktu yang 
signifikan pada fase maksimal speed $(\mathrm{P}<0,05)$.

\section{PEMBAHASAN}

Penelitian ini telah menunjukan bahwa dengan adanya pemasangan Neuromuscular taping menggunakan teknik kompresi yang bersifat konsentrik terjadi peningkatan pada explosive power dan kecepatan maksimal pada lari sprint 100 meter. Hal ini sesuai dengan penelitian sebelumnya dengan neuromuscular taping teknik aplikasi dekompresi yang bersifat eksentrik juga menunjukkan peningkatan pada otot gastrocnemious (Endaryanto, 2018) selain itu penelitian oleh Tsabatani juga menunjukkan hasil yang senada, yaitu terdapat pengaruh aplikasi NMT pada otot gastrocnemius dalam meningkatkan kecepatan lari pada atlet futsal di Surakarta (Tsabani, 2018). Berdasarkan penelitianpenelitian tersebut menunjukkan bahwa baik teknik dekompresi NMT berpengaruh terhadap peningkatan pada otot gastrocnemius sedangkan kompresi cocok untuk meningkatkan explosive power. Hasil penelitian menunjukkan bahwa teknik kompresi berpengaruh terhadap peningkatan explosive power dan memperpendek waktu tempuh pada lari sprint 100 meter, hal tersebut menunjukkan bahwa teknik kompresi cocok digunakan. Hal ini dikarenakan,
NMT teknik kompresi dapat menghasilkan stimulasi otot menjadi memendek dengan menghasilkan respon konsentrik sehingga akan meningkatkan kontraksi pada otot, dan tendon, serta menarik kulit, yang akan menimbulkan pengurangan aliran darah dan limfe. Selain itu karakteristik NMT teknik kompresi khusus memberikan pengaruh pada kompresi otot, tendon dan sendi untuk meningkatkan performa otot, efisiensi tendon, dan meningkatkan stabilitas sendi (Blow, 2012). Oleh karena itu, hal tersebut berpengaruh terhadap peningkatan explosive power dan kecepatan maksimal pada lari sprint 100 meter.

Meskipun beberapa literatur mengatakan bahwa neuromuscular taping banyak digunakan untuk pencegahan cedera dan mengurangi rasa nyeri dengan transmisi rangsangan exteroceptive dan propioceptive ke saraf pusat (Dewangga, 2018) Namun penelitian yang lain menunjukkan bahwa dengan pemasangan taping bersama-sama dengan latihan olahraga, dapat merangsang reseptor kulit lokal, dengan peran meningkatkan stabilitas dan kontrol lokal sendi. Oleh sebab itu wajar apabila teknik aplikasi tersebut mampu meningkatkan fungsional otot (Russo, 2018). Penggunaan NMT menimbulkan wrinkle sehingga menyebabkan terbukanya ruang antara kulit dan lapisan dibawahnya. Kemudian setelah 
ruang terbuka maka akan terjadi sirkulasi darah yang lancar, meningkatkan limfatik dan regenerasi jaringan yang bagus sehingga dalam melakukan gerakan berlari, otot mendapatkan asupan oksigen yang cukup (Tsabani, 2018).

Gastrocnemius, soleus, dan plantar fleksi berperan penting dalam meningkatkan kecepatan gerak. Otot sama-sama menghasilkan kekuatan selama berlari plantar fleksi menghasilkan kekuatan terbesar dari semua kelompok otot tungkai. Ketika kecepatan berlari menuju fase maksimum, soleus dan gastrocnemius juga menghasilkan kekuatan dan periode waktu yang semakin pendek (Adrian Lai et al., 2014) Efisiensi menghasilkan peningkatan kecepatan lari dengan pemendekan otot, karena tendon berkontribusi secara proporsional yang menimbulkan serat otot berkontraksi lebih efisien daripada terjadi elastisitas regangan tendon yang tidak dapat meningkatkan kecepatan lari secara maksimal ((Lai et al., 2014).

Berdasarkan hasilnya juga ditemukan perubahan peningkatan panjang langkah dan irama langkah pada dinamika fase maksimal speed jarak 30-60 meter. Peningkatan panjang langkah dan irama langkah berpengaruh terhadap kecepatan maksimal lari sprint 100 meter. Panjang langkah dan frekuensi langkah secara biomekanika dipengaruhi oleh massa tubuh dan tinggi badan individu atlet karena selain kemampuan fisik, masa otot berperan penting untuk akselerasi untuk mengatasi inersia dan meningkatkan panjang langkah, sedangkan tinggi badan yaang lebih besar bertujuan untuk menjaga kecepatan dan panjang langkah.

Sprint membutuhkan konsentrik dan eksentrik muscular cycle sehingga kedua teknik dekompresi maupun kompresi NMT dapat digunakan dalam menunjang performa sprint. Langkah cepat untuk mengembangkan kecepatan maksimal saat take off membutuhkan kontraksi eksentrik ke konsetrik bertujuan untuk efisiensi transisi waktu sesingkat mungkin. Pada saat take-off gastrocnemius meningkatkan kekakuan sebelum menyentuh permukaan. Peningkatan kekakuan pada otot besamaan dengan minimal gerakan pada ankle joint untuk memberikan stimulasi elastik energi dari eksentrik ke konsentrik (Maćkała and Mero, 2013).

\section{KESIMPULAN}

Aplikasi neuromuscular taping (NMT) teknik kompresi dapat meningkatan explosive power dan maximum speed lari 100 meter. 


\section{UCAPAN TERIMA KASIH}

Ucapan terima kasih saya sampaikan untuk pembimbing, keluarga, sahabat, semua pihak yang mendukung, dan seseorang yang selalu mendukung saya.

\section{REFERENSI}

Amin, Akhmad Alfajri.(2014). Aspek Kinesiologi pada Pelari Sprint. Article: Universitas Udayana.

Blow, D., (2012). Neuromuscular Taping from Theory to Practice. Milan:Arti Grafiche Colombo-Gessate

Davis, B. et al.2000. Physical Education and the Study of Sport. London: Harcourt Publishers. p. 237-238

Dewangga MW, Rahayu UB.(2018). The Effect of Neuromuscular Taping On The of Low Back Pain In The 8 th University Research Collquium: Universitas Muhammadiyah;332-

Didik Zafar. 2010. Mengajar dan melatih Atletik. Bandung: Rosdakarya.

Endaryanto, AH. 2018. Pengaruh Nuromuscular Taping Terhadap Kekuatan, Fleksiibilitas Otot Dan Waktu Tempuh Sprinter $100 \mathrm{M}$. Tesis: UNAIR.

Lai, A. et al. (2014) 'Tendon elastic strain energy in the human ankle plantarflexors and its role with increased running speed', Journal of Experimental Biology, 217(17), pp. 3159-3168. doi: 10.1242/jeb.100826.

Majumdar, A. and Robergs, R. (2011) 'The science of speed: Determinants of performance in the $100 \mathrm{~m}$ sprint: A response to Commentary', International Journal of Sports Science and Coaching, 6(3), pp. 479-493. doi:
10.1260/1747-9541.6.3.479.

Maćkała, K., Fostiak, M. and Kowalski, K. (2015) 'Selected determinants of acceleration in the $100 \mathrm{~m}$ Sprint', Journal of Human Kinetics, 45(1), pp. 135-148. doi: 10.1515/hukin-20150014.

Maćkała, K. and Mero, A. (2013) 'A kinematics analysis of three best 100 $\mathrm{m}$ performances ever', Journal of Human Kinetics, 36(1), pp. 149-160. doi: 10.2478/hukin-2013-0015.

Mackala, K., (2007). Optimisation of performance through kinematic analysis of the different phases of the 100 meters. IAAF, 22 (2), 7-16.

Mero A, Luhtanen P, Komi PV.1986. Segmental contribution to velocity of centre of gravity during contact at different speeds in male and female sprinters. J Hum Movement Stud, 12, pp. 215-235.

Semmler JG, Enoka RM. 2000. Neural contributions to the changes in muscle strength. V V.M. Zaitorsky (Ur.), Biomechanics in sport: The scientific basis of performance, (str. 3-20), Oxford: Blackwell Science.

Tsabatani Hanik.2018. Pengaruh Aplikasi Neuromuscular Taping pada Otot Gastrocnemious untuk Meningkatkan Kecepatan Lari Atlet Futsal Universitas Muhammadiyah Surakarta [Skripsi]. Surakarta: Universitas Muhammadiyah.

Veeramani.(2018). Bolt Biomechanical analysis of Sprints and Hurdles Events at the 2009 IAAF World Championship in Athletics and Zohri Video Analysis of Race: IAAF. 